\section{Р.Н.Молчанов И.С.Шпонька}

ГУ «Днепропетровская медицинская академия МЗ Украины»

Ключевые слова: рак мочевого пузыря CD95, p53, Ki-67, Bcl-2, BAX, Е-кадгерин и $\beta$-катенин, ЦОГ-2, eNOS, iNOS.

Надійшла: 05.09.2014

Прийнята: 22.09.2014
DOI: https://doi.org/10.26641/1997-9665.2014.3.42-49

УДК 616.62-006.6-02-002-036.1-074/-076-097

\section{ИММУНОГИСТОХИМИЧЕСКАЯ ОЦЕНКА РАКА МОЧЕВОГО ПУЗЫРЯ, ПРОТЕ- КАЮЩЕГО НА ФОНЕ ХРОНИЧЕСКОГО ВОСПАЛЕНИЯ}

Исследование проведено в рамках научно-исследовательской работы «Изучение влияния воспалительного прочесса на возникновение и развитие рака органов мочеполовой системы» (номер государственной регистрации 0103U002379).

Реферат. Цель исследования - установление наличия связи экспрессии маркеров CD95, p53, Ki-67, Bcl-2, BAX, Е-кадгерина, $\beta$-катенина, ЦОГ-2, eNOS и iNOS с наличием сопутствующего воспалительного процесса у больных раком мочевого пузыря. Выполнено иммуногистохимическое исследование экспрессии указанных маркеров в биоптатах, полученных у 44 больных раком мочевого пузыря, разделенных на 2 группы сравнения в соответствии с наличием сопутствующей инфекции мочевых путей. Установлено наличие повышение экспрессии ЦОГ-2 и iNOS, а также изменения характера связи экспрессии маркеров пролиферации, апоптоза и клеточной адгезии в группах сравнения, которые могут быть причиной изменения характера протекания опухолевого процесса на фоне воспалительного процесса.

Morphologia. - 2014. - T. 8, № 3. - C. 42-49.

(C) Р.Н.Молчанов, И.С.Шпонька, 2014

\rob_molch@yahoo.com

Molchanov R.N., Shpon'ka I.S. Immunohistochemical assessment of bladder cancer on the background of the chronic inflammation.

ABSTRACT. Background. The effect of chronic inflammation caused by uropathogenic strains of bacteria on bladder cancer is a little-studied subject. Objective of the research was to investigate the interrelationship between the expression of CD95, p53, Ki-67, Bcl-2, BAX, E-cadherin, $\beta$-catenin COX-2, eNOS, iNOS markers and the presence of concomitant urinary tract infection. Methods. Tumor specimens taken from 44 patients with superficial bladder cancer were divided in two groups according to the absence (I) or presence (II) of urinary tract infection. The level of markers expression was detected with the help of immunohistochemical methods. Specimens of bladder wall from 8 patients with benign prostate hyperplasia were used as a control. Results. Statistically significant increase of p53, Ki67 expression and decrease of CD95, BAX, Ecadherin and $\beta$-catenin expression in tumor tissue comparing with the control was found $(p<0,05)$. It is established that in the group I specimens expression of iNOS $(1,0 \pm 0,87)$ in tumor tissue was less pronounced than in group II $(1,95 \pm 0,57)(p<0,05)$. Presence of strong positive correlation between p53 and Ki67, bcl-2 and BAX expression in group I; bcl-2 and Ki67, BAX and $\beta$-catenin expression in group II were revealed $(\mathrm{p}<0,001)$. Conclusions. Decrease of apoptotic activity and adhesive properties, increase of proliferation of urothelium are typical characteristics of bladder cancer. Increase of the expression of iNOS on the background of the inflammatory process may be evidence in favor of the negative effects of inflammation on the course of cancer. The difference in interrelationships between the levels of apoptotic and proliferation markers expression in group I and II evidence changes of their interaction and can be the reason of unusual tumor development on the background of inflammatory process.

Key words: bladder cancer, CD95, p53, Ki-67, Bcl-2, BAX, E-cadherin, $\beta$-catenin, COX-2, NOS.

\title{
Citation:
}

Molchanov RN, Shpon'ka IS. [Immunohistochemical assessment of bladder cancer on the background of the chronic inflammation]. Morphologia. 2014;8(3):42-9. Russian.

\section{Введение}

Переходноклеточный рак мочевого пузыря является наиболее частым злокачественным заболеванием органов мочевыделительной системы. В 75\% случаев рак мочевого пузыря диагностируют в ранней стадии, для которой стандартными методами лечения являются трансуретральная резекция мочевого пузыря с последую- щей адъювантной внутрипузырной химио- или иммуннотерапией. Частые рецидивы и связанная с ними прогрессия, которые наблюдаются при поверхностном раке мочевого пузыря в $60-70 \%$ и $15 \%$ соответственно, требуют пожизненного наблюдения и лечения. Изучение факторов риска развития РМП является важным компонентом поиска эффективных методов профилактики и 
лечения первичного заболевания и его рецидивов. Одним из доказанных факторов риска является хронический цистит, развивающийся на фоне шистосомоза [1]. В то же время влияние хронического воспаления, вызванного уропатогенными штаммами бактерий на течение рака мочевого пузыря, является малоизученным вопросом.

Развитие злокачественных изменений уротелия, приводящих к развитию рака мочевого пузыря и его рецидивов, являются многостадийным процессом. В основе постепенно наступающих изменений лежит ряд явлений, происходящих на генетическом уровне, включающих активацию онкогенов, инактивацию геновсупрессоров образования опухолей и нарушением генов, кодирующих процесс апоптоза [2].

Одним из механизмов индукции апоптоза является система рецептора смерти Fas (Apo1/CD95) и Fas лиганда (FasL). Повреждение Fas гена может приводить к снижению его функции апоптоза и служить одним из патогенетических звеньев развития рака мочевого пузыря [3].

Важным звеном регуляции клеточного цикла, выполняющим функцию супрессора образования злокачественных опухолей, является транскрипционный фактор p53. Возникновение мутаций гена р53 является наиболее частым генетическим повреждением, наблюдающимся в раковых опухолях человека [3].

В регуляции апоптоза участвует семейство протеинов bcl-2, в котором различают проапоптозные и антиапоптозные белки. Нарушение их баланса, связанные с мутациями и изменению экспрессии соответствующих генов играют важную роль в канцерогенезе [4].

Кi-67 является ядерным протеином, связанным с пролиферацией клеток и транскрипцией рибосомальной РНК. Увеличение фракции Кі67+ опухолевых клеток связано с ухудшением прогноза течения ряда опухолей, в том числе и рака мочевого пузыря [5].

В последнее время объектом исследования являются кадгерин-катениновые комплексы, определяющие способность к межклеточной адгезии. Кадгерины представляют собой трансмембранные протеины, регулирующие кальций зависимую межклеточную адгезию и посредством внутриклеточных протеинов - катенинов связаны с цитоскелетом [6]. При большинстве человеческих раков дисфункция Е-кадгеринкатенинового комплекса связана со снижением клеточной и тканевой дифференцировки, большей инвазивностью и метастатическим потенциалом [7].

Одним из важных звеньев канцерогенеза считается циклооксигеназа (ЦОГ) - фермент, участвующий в синтезе простагландинов которые стимулируют опухолевый рост путем стимуляции клеточной пролиферации, ангиогенеза, подавления апоптоза и иммунной защиты [8].
В воспалительной теории канцерогенеза ведущая роль отводится оксидативному стрессу. Он является причиной повреждения ДНК кислородными радикалами, эндогенными источниками которых являются воспалительные клетки, такие как нейтрофилы, макрофаги и эозинофилы. Признаком оксидативного стресса также является изменение уровней оксида азота (NO) и его синтаз (NOS) [9].

Изучение перечисленных выше маркеров, определяющих поведение опухолевых клеток, а также исследование их взаимной связи и зависимости от клинико-патологических особенностей опухолей является актуальным с точки зрения оценки влияния факторов риска и эффективности различных лечебных стратегий и на протекание опухолевого процесса.

Целью исследования явилось установление наличия связи экспрессии маркеров CD95, p53, Ki-67, Bcl-2, BAX, Е-кадгерина и $\beta$-катенина, циклооксигеназы 2 типа (ЦОГ-2), эндотелиальной (eNOS) и индуцированной синтаз (iNOS) c клинико-патологическими характеристиками поверхностного рака мочевого пузыря и наличием сопутствующего воспалительного процесса.

\section{Материалы и методы}

Исследовали биопсийный материал, полученный у 44 пациентов с переходноклеточным раком мочевого пузыря в стадия $\mathrm{T}_{\mathrm{a}} \mathrm{N}_{0} \mathrm{M}_{0}$ и $\mathrm{T}_{1} \mathrm{~N}_{0} \mathrm{M}_{0}$ умеренного и высокого уровня дифференцировки. Пациенты разделены на 2 группы по 22 человека в соответствие с отсутствием (I группа, средний возраст $61,7 \pm 10,7(\mathrm{M} \pm \sigma)$ лет) ли наличием (II группа, средний возраст 64,2 $\pm 9,4$ $(\mathrm{M} \pm \sigma)$ лет) сопутствующей инфекции мочевых путей. Контрольная (III) группа представлена 8 пациентами (средний возраст $65,8 \pm 4,0 \quad(\mathrm{M} \pm \sigma)$ лет) с доброкачественной гиперплазией предстательной железы, у которых биоптаты получены во время трансуретральной резекции предстательной железы из области шейки мочевого пузыря.

Биоптаты для исследования получали при трансуретральной (39) или открытой (5) резекции мочевого пузыря на границе опухоли и интактной ткани стенки мочевого пузыря на глубину мышечного слоя.

Для проведения морфологического исследования использовали парафиновые блоки операционного и биопсийного материала. После проведения тщательного рутинного патогистологического исследования, срезы толщиной 4-6мкм наносили на адгезивные предметные стекла SuperFrost Plus, затем депарафинизировали согласно принятым стандартам. После депарафинизации для восстановления антигенных свойств ткани проводили тепловую индукцию эпитопного (антигенного) восстановления (HIER - heat induction of epitope retrieval) путем нагревания в цитратном буфере с $\mathrm{pH}=6,0$ в автоклаве (8 минут 
при температуре $+121^{\circ} \mathrm{C}$ ).

С целью определения экспрессии маркеров мы использовали спектр антител, который включал маркеры p53 (клон SP5), Ki-67 (клон SP6 (LabVision)), bcl-2 (клон 100/D5 (LabVision), Bax, CD95/Fas, $\beta$-Catenin, E-cadgerin (клон NCH-38), Nitric Oxide Synthase inducible (iNOS), Nitric Oxide Synthase endothelial (eNOS), COX-2.

Инкубацию срезов с первичными антителами проводили во влажных камерах при температуре $23-25^{\circ} \mathrm{C}$ в течение 30 минут. Титр антител подбирался индивидуально для каждого маркера. Следующий этап иммунногистохимического (ИГХ) исследования проводили с использованием систем визуализации UltraVision Quanto и UltraVision LP (LabVision), идентификация реакций проводилась с помощью хромогена $\mathrm{DAB}$ под контролем микроскопа на протяжении от 20 секунд до 3 минут.

Для дифференцирования структур тканей срезы дополнительно окрашивали гематоксилином Майера.

Количественные и качественные показатели экспрессии маркеров изучали как минимум на 10 случайно выбранных полях зрения микроскопа гистологических срезов при увеличении $\times 100, \times 400$. Оценка экспрессии каждого маркера проводилась индивидуально в соответствии с рекомендациями других исследователей.

При оценке иммуногистохимической (ИГХ) окраски использовался полуколичественный метод, в соответствии с которым выделяли 4 категории: 0 - негативная реакция (окраска $<5 \%$ клеток), 1 - слабая окраска (позитивно окрашены отдельные клетки или слабая окраска всего эпителия), 2 - умеренно выраженная окраска (большая часть позитивно окрашенных клеток) и 3 интенсивная окраска (практически все клетки эпителия позитивно окрашены). Интенсивность ИГХ окраски при исследовании экспрессии Кі67 выражали в \% клеток с позитивной реакцией.

Для статистической оценки использовали стандартный описательный, непараметрические для оценки различия групп (U-критерий МаннаУитни), корреляционный (метод ранговой корреляции Спирмена) анализы. Достоверность статистической значимости различий, уровней значимости и достоверность корреляционных коэффициентов принимались при $\mathrm{p}<0,05$.

\section{Результаты и их обсуждение}

При оценке клинико-патологических критериев в I и II группах мы не выявили достоверных различий в сравниваемых группах по таким параметрам как возраст, пол, уровень дифференцировки опухоли, стадия или частота рецидива. У пациентов с сопутствующим воспалением в ряде случаев наблюдалась плоскоклеточная метаплазия.

Образцы опухоли и подлежащей ткани, полученные у пациентов II группы, идентифицировались достаточно четко по наличию инфильтрации ткани полиморфноядерными лейкоцитами.

Результаты полуколичественного исследования иммуногистохимических маркеров представлены в таблице 1.

Таблица 1

Показатели степени экспрессии исследованных ИГХ маркеров у пациентов с раком мочевого пузыря $(\mathrm{M} \pm \sigma)$

\begin{tabular}{lccc}
\hline \multicolumn{1}{c}{ Маркер } & I группа & II группа & Контроль \\
& $\mathrm{N}=22$ & $\mathrm{~N}=22$ & $\mathrm{~N}=8$ \\
\hline CD95 & $1,23 \pm 0,43^{*}$ & $1,09 \pm 0,29^{*}$ & $1,75 \pm 0,46$ \\
P53 & $0,36 \pm 0,49^{*}$ & $0,32 \pm 0,47^{*}$ & 0 \\
Ki67 (\%) & $27,55 \pm 22,26^{*}$ & $36,64 \pm 20,71^{*}$ & $7,13 \pm 2,3$ \\
bcl-2 & $0,68 \pm 0,89$ & $0,59 \pm 0,73$ & $0,25 \pm 0,46$ \\
BAX & $1,36 \pm 0,49^{*}$ & $1,73 \pm 0,7$ & $2,38 \pm 0,74$ \\
E-кадгерин & $0,68 \pm 0,84^{*}$ & $0,64 \pm 0,66^{*}$ & $1,63 \pm 0,52$ \\
$\beta$-катенин & $2,09 \pm 0,68$ & $1,77 \pm 0,81^{*}$ & $2,5 \pm 0,53$ \\
COX-2 & $1,55 \pm 1,01^{*}$ & $1,55 \pm 0,73^{*}$ & 0 \\
iNOS & $1,0 \pm 0,87^{\dagger *}$ & $1,95 \pm 0,57^{* *}$ & 0 \\
eNOS & $0,95 \pm 0,65$ & $1,05 \pm 0,49$ & $1,37 \pm 0,51$ \\
\hline
\end{tabular}

Примечания: *- $<0,05$ - достоверное отличие от показателей контрольной группы; ${ }^{\dagger}$ - p<0,05 - достоверное отличие показателей II и III групп.

В контрольной группе мы выявили умеренно выраженную ИГХ окраску CD95+ эпителия $(1,75 \pm 0,46)$. В биоптатах пациентов с опухолями мочевого пузыря окраска была менее интенсивной, определялись островки опухолевых клеток без окрашивания. Показатель интенсивности окраски CD95+ в I и II группах исследованных пациентов были достоверно $(\mathrm{P}<0,05)$ менее интенсивными и составили $(1,23 \pm 0,43)$ и $(1,09 \pm 0,29)$ соответственно. Полной потери окрашивания ткани на предмет маркера $\mathrm{CD} 95+$ мы не наблюдали ни у одного пациента. В то же время мы не наблюдали достоверного различия данного показателя в исследованных группах 
пациентов (P>0,05). Снижение интенсивности ИГХ CD95+ реакции можно объяснить тем, что большинство было представлено поверхностными опухолями, в то время, как полное отсутствие экспрессии CD95+ обычно наблюдается главным образом при инвазивных опухолях [10].

ИГХ окраска на предмет экспрессии мутантного онкопротеина p53 была негативной в контрольной группе образцов. Во всех исследованных опухолях мы отметили позитивное окрашивание. При исследовании экспрессии р53 в опухолевой ткани в группах I и II мы не выявили достоверного различия интенсивности позитивного окрашивания, которая составила $0,36 \pm 0,49$ и $0,32 \pm 0,47$ соответственно ( $p>0.05)$. Полученные результаты соответствуют современным данным о том, что как опухоль, так и воспалительный процесс в мочевом пузыре может способствовать повышению экспрессии р53 [3].

Выявлено повышение среднего значения bcl-2 в ткани опухоли I $(0,68 \pm 0,89)$ и II $(0,59 \pm 0,73)$ групп по сравнению с контрольными образцами $(0,25 \pm 0,46)$, хотя различие не было статистически достоверным (Р>0,05). Показатель экспрессии Вах в биоптатах I группы пациентов $(1,36 \pm 0,49)$ достоверно $(\mathrm{P}<0,05)$ отличался в сторону снижения по сравнению с контрольной группой $(2,38 \pm 0,74)$. Во II группе он достоверно не отличался от группы контроля $(1,73 \pm 0,7)$. Мы не выявили достоверного отличия интенсивности иммуногистохимической реакции bcl-2 и Bax в биоптатах, содержащих опухоль с воспалением и без воспаления. Согласно данным литературы при цистите наблюдается повышение экспрессии bcl-2, при этом достоверного различия не наблюдается при специфическом (шистосоматозном) и неспецифическом цистите. В то же время, в опухоли, возникшей на фоне шистосомоза, наблюдается более выраженная экспрессия этого маркера [2]. Известно, что Вах окрашивание значительно слабее в клетках переходноклеточного рака по сравнению с нормальной тканью мочевого пузыря. Снижение экспрессии Вах играет важную роль в развитии переходноклеточного рака, ее отсутствие связано с уменьшенной выживаемостью пациентов [11].

При ИГХ исследовании ядерного протеина Ki-67 установлено, что средний процент позитивно окрашенных клеток достоверно отличался в сторону повышения у пациентов с опухолью мочевого пузыря по сравнению с показателями в контрольной группе $(7,13 \pm 2,3 \%)(\mathrm{P}<0,05)$. Вследствие выраженного разброса данных не удалось установить достоверного различия экспрессии Кі -67 в опухолях при наличии сопутствующего воспалительного процесса (II группа) $36,64 \pm 20,71 \%$,и в I группе, где установлен показатель $27,55 \pm 22,26 \%(\mathrm{P}>0,05)$.

Известно, Кі-67 является прогностическим фактором при различных видах лечения рака мочевого пузыря, независимым прогностическим фактором продолжительности безрецидивного периода. Повышение экспрессии Кi-67 по сравнению с нормой выявлено при специфическом (шистоматозном) и неспецифическом циститах (без значимых различий в пределах группы сравнения). В то же время, не выявлено различия экспрессии Кі-67 у пациентов с раком мочевого пузыря, протекающим на фоне шистосомоза и обычного рака мочевого пузыря [2].

Исследованы молекулы адгезии Е-кадгерин, $\beta$-катенин, являющиеся основными медиаторами клеточного взаимодействия в эпителиальной ткани. Установлено, что в контрольной группе наблюдалась выраженная иммуногистохимическая реакция клеточных мембран как в отношениии Е-кадгерина - 1,63 $\pm 0,52$, так и беттакатенина - 2,5 $\pm 0,53$. В биоптатах с опухолями мы выявили снижение данных показателей: Екадгерин - $0,68 \pm 0,84$ и $0,64 \pm 0,66 ; \beta$-катенин $2,09 \pm 0,68$ и $1,77 \pm 0,81$ в I и II группах, соответственно, которое достигало статистической значимости $(\mathrm{P}<0,05)$ по сравнению с группой контроля (кроме показателя $\beta$-катенина в I группе). При сравнении показателей между исследованными группами достоверного различия не установлено $(\mathrm{P}>0,05)$. По данным литературы в нормальном уротелии наблюдается выраженная мембранная экспрессия Е-кадгерина, подверженная индивидуальным вариациям. Потеря мембранной Екадгерин иммунореактивности коррелирует с высокой градацией развитой стадией и плохим прогнозом рака мочевого пузыря. Отмечено снижение экспрессии Е-кадгерина в уротелии при наличии интерстициального цистита $[12,13]$.

При наличии воспалительного процесса экспрессия ЦОГ-2 наблюдалась как в эпителии, так и в стромальном компоненте, в то время как при опухоли мочевого пузыря без воспалительного процесса позитивная реакция наблюдалась только в эпителии. При этом достоверного различия в группах больных с опухолями не установлено ( $>0.05)$. Выявлено отсутствие экспрессии ЦОГ-2 с незначительными участками позитивной реакции в нормальной ткани мочевого пузыря, полученной при биопсии у пациентов контрольной группы (рис. 1).

Исследование эпителиальной и индуцибельной NO синтазы (eNOS, iNOS ) как в эпителии биоптатов контрольной группы $(1,37 \pm 0,51)$, так и в опухолевых клетках - $(0,95 \pm 0,65$ и $1,05 \pm 0,49)$ биоптатов I и II групп больных соответственно. Мы не выявили достоверного различия экспрессии данного маркера при сравнении как с контрольной группой так и в группах иследования (P>0,05). Полученные результаты соответствует данным Lin et al., 2003 которые также установили наличие экспрессии eNOS как в нормальном эндотелии мочевого пузыря, так и клетках рака мочевого пузыря [14]. 


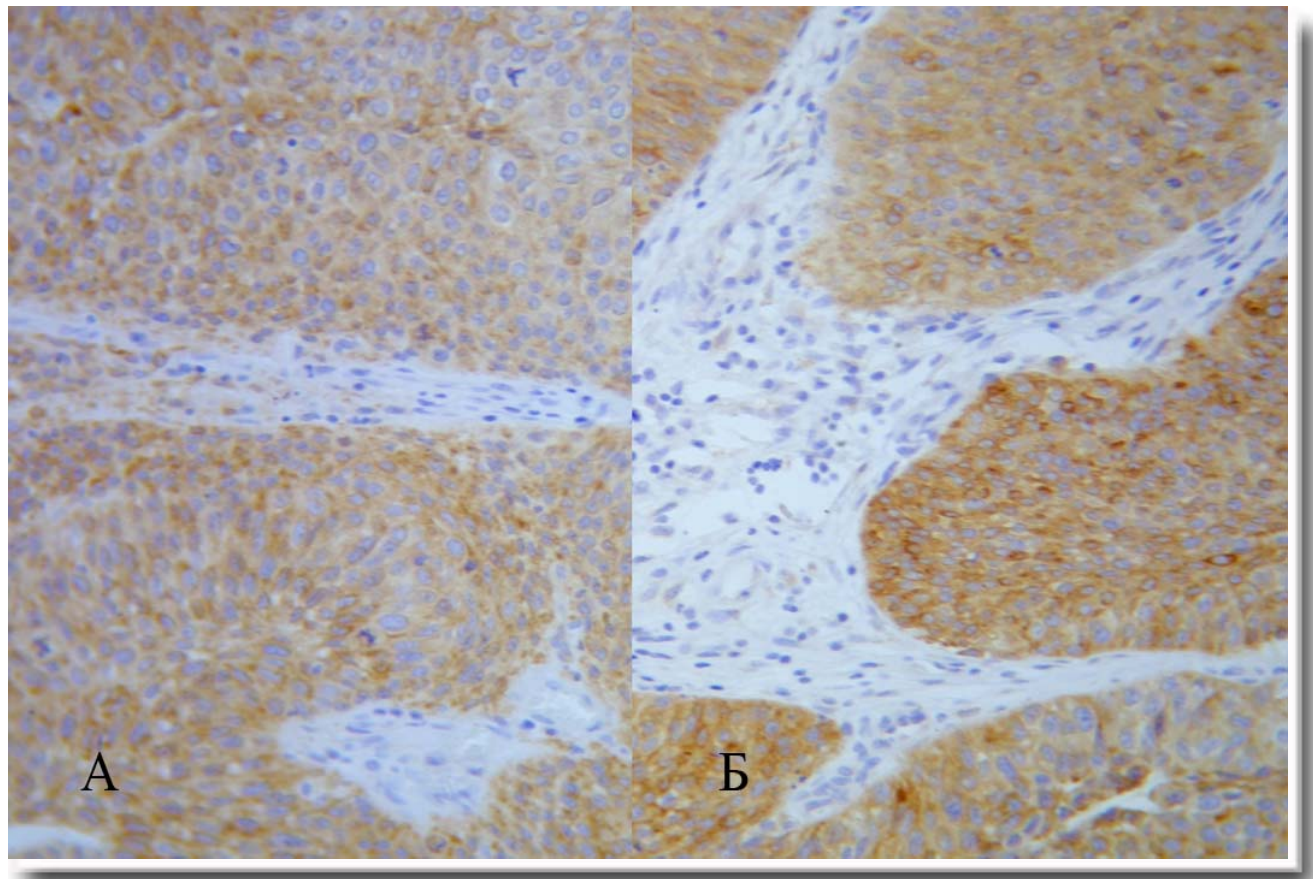

Рис.1. Рак мочевого пузыря. ЦОГ-2 + клетки в строме и эпителии опухоли при наличии сопутствующего воспаления (А) и в эпителии при отсутствии воспаления (Б). ИГХ метод, дополнительное окрашивание гематоксилином Майepa. $\times 200$.

Экспрессия iNOS выявленная в I группе $(1,0 \pm 0,87)$ была достоверно $(\mathrm{P}<0,05)$ ниже по сравнению с II группой $(1,95 \pm 0,57)$. В биоптатах контрольной группы пациентов экспрессия данного маркера не выявлена (рис. 2).

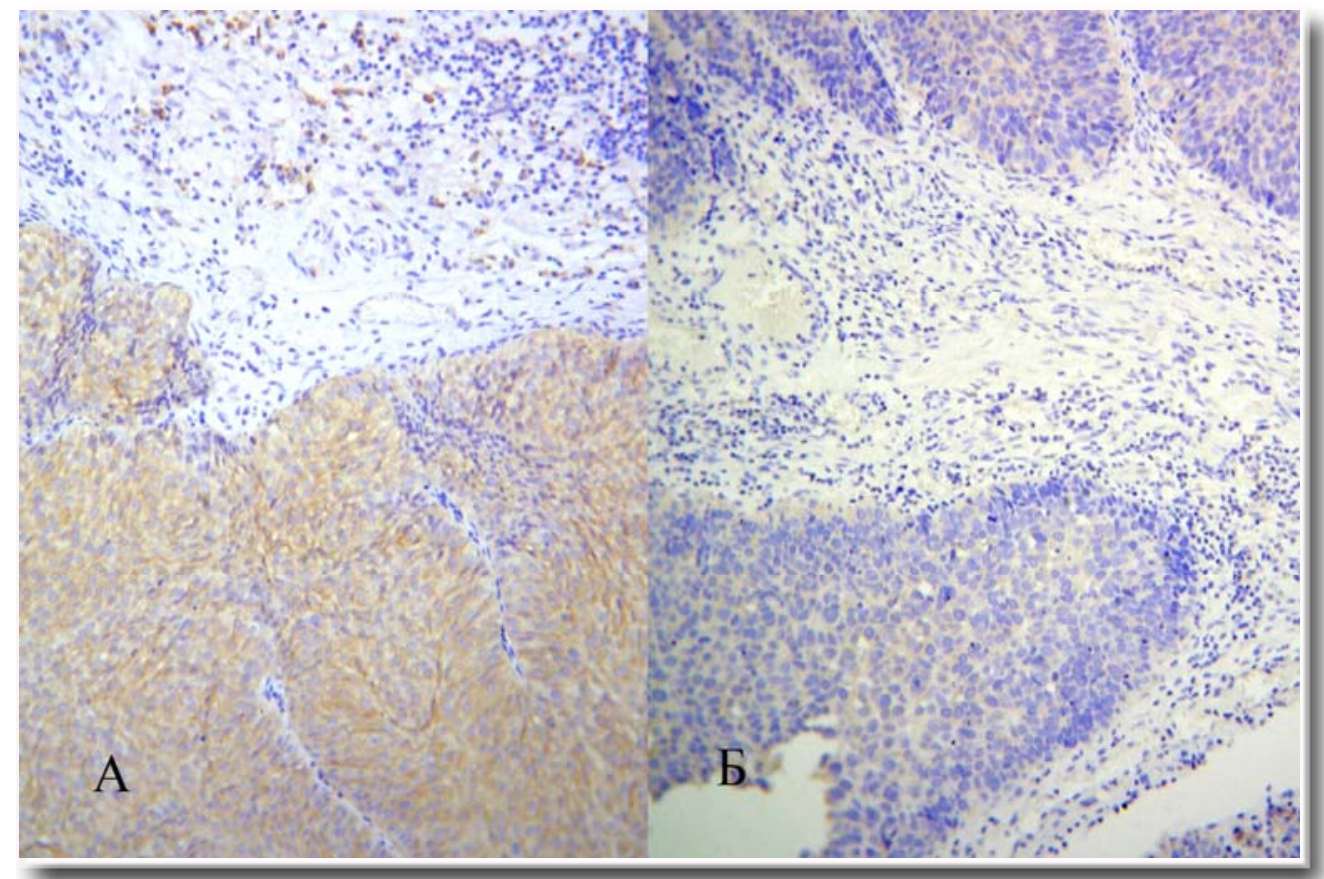

Рис.2. Рак мочевого пузыря. iNOS + клетки в строме и эпителии опухоли при наличии (А) и отсутствии (Б) сопутствующего воспаления. ИГХ метод, дополнительное окрашивание гематоксилином Майера. ×100.

Исследование эпителиальной и индуцибельной NO синтазы (eNOS, iNOS ) как в эпителии биоптатов контрольной группы $(1,37 \pm 0,51)$, так и в опухолевых клетках - $(0,95 \pm 0,65$ и $1,05 \pm 0,49)$ биоптатов I и II групп больных соответственно. Мы не выявили достоверного различия экспрес- 
сии данного маркера при сравнении как с контрольной группой так и в группах иследования $(\mathrm{P}>0,05)$. Полученные результаты соответствует данным Lin et al., 2003 которые также установили наличие экспрессии eNOS как в нормальном эндотелии мочевого пузыря, так и клетках рака мочевого пузыря [14].

Экспрессия iNOS выявленная в I группе $(1,0 \pm 0,87)$ была достоверно $(\mathrm{P}<0,05)$ ниже по сравнению с II группой $(1,95 \pm 0,57)$. В биоптатах контрольной группы пациентов экспрессия данного маркера не выявлена.

По данным современных исследований iNOS экспрессируется в клетках, представляющих и окружающих опухоль мочевого пузыря. Предполагается, что высокий уровень NO в моче пациентов с раком мочевого пузыря может быть обусловлен активностью iNOS не только в опухолевой, но и в нормальной ткани мочевого пузыря. Гетерогенное окрашивание iNOS обнаружено в опухолевых клетках поверхностных и инвазивных опухолей, в то время как практически отсутствует в нормальном уротелии мочевого пузыря [15]. Кроме того, экспрессия iNOS связана с воспалительной реакцией слизистой мочевого пузыря различного генеза [16].

С целью обнаружения взаимных связей экспрессии исследуемых маркеров, а также их связи с клинико-морфологическими характеристиками мы использовали корелляционный анализ Спирмена (табл.2).

Таблица 2

Корреляции показателей экспрессии ИГХ маркеров у пациентов с раком мочевого пузыря

\begin{tabular}{lcccc}
\hline \multicolumn{1}{c}{ Показатели } & \multicolumn{2}{c}{ Группа I $(\mathrm{N}=22)$} & \multicolumn{2}{c}{ Группа II $(\mathrm{N}=22)$} \\
\cline { 2 - 5 } & Spearman $(\mathrm{R})$ & $\mathrm{p}$ & Spearman $(\mathrm{R})$ & $\mathrm{p}$ \\
\hline Дифференцировка\& Кi67 & 0,10 & $>0,05$ & $\mathbf{0 , 6 3}$ & $<\mathbf{0 , 0 1}$ \\
Дифференцировка\& $\beta$-катенин & 0,06 & $>0,05$ & $\mathbf{0 , 4 8}$ & $<\mathbf{0 , 0 5}$ \\
Метаплазия \& Кi-67 & - & - & $\mathbf{0 , 6 0}$ & $<\mathbf{0 , 0 1}$ \\
Метаплазия \& bcl-2 & - & - & $\mathbf{0 , 5 5}$ & $<\mathbf{0 , 0 1}$ \\
Метаплазия \& $\beta$-катенин & - & - & $\mathbf{0 , 4 4}$ & $<0,05$ \\
р53 \& Кі-67 & $\mathbf{0 , 8 4}$ & $<\mathbf{0 , 0 0 1}$ & 0,25 & $>0,05$ \\
bcl-2 \& Вах & $\mathbf{0 , 8 6}$ & $<\mathbf{0 , 0 0 1}$ & $\mathbf{0 , 7 1}$ & $<\mathbf{0 , 0 0 1}$ \\
Кi-67 \& bсl-2 & 0,09 & $>0,05$ & $\mathbf{0 , 8 9}$ & $<\mathbf{0 , 0 0 1}$ \\
bcl-2 \& $\beta$-катенин & 0,07 & $>0,05$ & $\mathbf{0 , 7 3}$ & $<\mathbf{0 , 0 0 1}$ \\
\hline
\end{tabular}

Мы установили, что в группе пациентов с сопутствующей инфекцией мочевых путей наблюдается прямая связь средней силы $(\mathrm{p}<0,05)$ между такими патоморфологическими показателями, как уровень дифференцировки, наличия метаплази и Ki67, bcl-2, eNOS, $\beta$-катенин.

В I группе пациентов с опухолями без сопутствующего воспалительного процесса выявлена прямая сильная связь экспрессии р53 и протеина Ki-67, отражающего пролиферативные процессы $(\mathrm{R}=0,84, \mathrm{p}<0,001)$.

Исследования корреляции экспрессии bcl-2 показало наличие сильной прямой связи с экспрессией Кi-67 ( $\mathrm{R}=0,89, \mathrm{p}<0,001)$, и $\beta$-катенина $(\mathrm{R}=0,73, \mathrm{p}<0,001)$, во II группе пациентов.

В обеих группах наблюдалась сильная связь экспрессии bcl-2 и $\mathrm{Bax}(\mathrm{R}=0,86$ и $0,71, \mathrm{p}<0,001)$.

Для большинства исследованных маркеров не выявили статистически достоверных коррелятивных связей с клинико-морфологическими характеристиками исследованных опухолей. Данный факт, по-видимому, связан с тем, что объектом исследований являются поверхностные опухоли умеренной и высокой степени дифференцировки с основным отличием - наличием сопутствующего воспалительного процесса. Приведенные выше литературные данные свиде- тельствуют о том что подобные связи обычно выявляются при исследовании опухолей высокой градации в инвазивных стадиях, и характерными для них клиническими особенностями (метастазирование, выживаемость и т.д).

\section{Выводы}

1. В биоптатах опухолевой ткани пациентов с поверхностным раком мочевого пузыря отмечается статистически достоверное повышение маркеров p53, Ki67 и снижение CD95, BAX, Eкадгерина, $\beta$-катенина по сравнению с контрольной группой, что свидетельствует о снижении активности апоптоза, повышении пролиферации и снижении адгезивных свойств уротелия.

2. Повышение экспрессии ЦОГ-2 и $\mathrm{NOS}$ в опухолевой ткани создает условия, благоприятные для дальнейшего развития опухоли. Достоверное увеличение экспрессии iNOS на фоне воспалительного процесса может свидетельствовать в пользу негативного воздействия воспаления на течение опухолевого процесса.

3. Наличие прямой сильной связи между экспрессией ИГХ маркеров p53 и Ki67, bcl-2 и BAX в биоптатах пациентов I группы и bcl-2 c Ki67, BAX, и $\beta$-катенина, а также некоторых маркеров с метаплазией и уровнем дифференцировки в биоптатах пациентов II группы, свиде- 
тельствует об изменении характера взаимодействия исследованных факторов на фоне воспалительного процесса и может быть причиной изменения характера протекания опухолевого процесса.

\section{Перспективы дальнейших разработок}

Планируется дальнейшее изучение влияния воспалительного процесса на клинические характеристики опухолевого процесса с целью оптимизации профилактики и лечения опухолей мочевого пузыря и их рецидивов.

\section{Литературные источники References}

1. Burger M, Catto JW, Dalbagni G, Grossman HB, Herr H, Karakiewicz P, et al. Epidemiology and risk factors of urothelial bladder cancer. European urology. 2013;63(2):234-41. doi: 10.1016/j.eururo.2012.07.033. PMID: 22877502.

2. Abdulamir AS, Hafidh RR, Kadhim HS, Abubakar F. Tumor markers of bladder cancer: the schistosomal bladder tumors versus nonschistosomal bladder tumors. J Exp Clin Cancer Res. 2009;28:27. doi: 10.1186/1756-9966-28-27. PMID: 19243595; PMCID: PMC2650688.

3. Ruddon RW. Cancer biology. 4th ed. Oxford; New York: Oxford University Press; 2007. $\mathrm{XIV}, 530 \mathrm{p}$.

4. Laulier C, Lopez BS. The secret life of Bcl2: apoptosis-independent inhibition of DNA repair by Bcl-2 family members. Mutat Res. 2012;751(2):247-57. doi: 10.1016/j.mrrev.2012.05.002. PMID: 22677530.

5. Bullwinkel J, Baron-Luhr B, Ludemann A, Wohlenberg C, Gerdes J, Scholzen T. Ki-67 protein is associated with ribosomal RNA transcription in quiescent and proliferating cells. J Cell Physiol. 2006;206(3):624-35. doi: 10.1002/jcp.20494. PMID: 16206250 .

6. Romanenko A, Morimura K, Kinoshita A, Wanibuchi H, Vozianov A, Fukushima S. Aberrant expression of E-cadherin and beta-catenin in association with transforming growth factor-beta1 in urinary bladder lesions in humans after the Chernobyl accident. Cancer science. 2006;97(1):4550. doi: CAS [pii]10.1111/j.13497006.2005.00131.x. PMID: 16367920.

7. Koksal IT, Ates M, Danisman A, Sezer C, Ciftcioglu A, Karpuzoglu G. Reduced E-cadherin and alpha-catenin expressions have no prognostic role in bladder carcinoma. Pathol Oncol Res. 2006;12(1):13-9. doi: PAOR.2006.12.1.0013. PMID: 16554911.

8. Marks F, Furstenberger G, Muller-Decker K. Tumor promotion as a target of cancer prevention. Recent Results Cancer Res. 2007;174:37-47. PMID: 17302183.

9. Heller A. Apoptosis-inducing high (.)NO concentrations are not sustained either in nascent or in developed cancers. ChemMedChem.
2008;3(10):1493-9. doi: 10.1002/cmdc.200800257. PMID: 18759245.

10. Yamana K, Bilim V, Hara N, Kasahara T, Itoi $\mathrm{T}$, Maruyama $\mathrm{R}$, et al. Prognostic impact of FAS/CD95/APO-1 in urothelial cancers: decreased expression of Fas is associated with disease progression. Br J Cancer. 2005;93(5):544-51. doi: 10.1038/sj.bjc.6602732. PMID: 16091761; PMCID: PMC2361597.

11. Gonzalez-Campora R, Davalos-Casanova G, Beato-Moreno A, Garcia-Escudero A, Pareja Megia MJ, Montironi R, et al. BCL-2, TP53 and $\mathrm{BAX}$ protein expression in superficial urothelial bladder carcinoma. Cancer Lett. 2007;250(2):292-9. doi: S0304-3835(06)00566-0 [pii]; 10.1016/j.canlet.2006.10.011. PMID: 17126995.

12. Bryan RT, Atherfold PA, Yeo Y, Jones LJ, Harrison RF, Wallace DM, et al. Cadherin switching dictates the biology of transitional cell carcinoma of the bladder: ex vivo and in vitro studies. J Pathol. 2008;215(2):184-94. doi: 10.1002/path.2346. PMID: 18393367.

13. Shie JH, Kuo HC. Higher levels of cell apoptosis and abnormal E-cadherin expression in the urothelium are associated with inflammation in patients with interstitial cystitis/painful bladder syndrome. BJU Int. 2011;108(2 Pt 2):E136-41. doi: 10.1111/j.1464-410X.2010.09911.x. PMID: 21166752 .

14. Alvarez V, Lodillinsky C, Umerez S, Sandes E, Eijan AM. Inhibition of bacillus CalmetteGuerin-induced nitric oxide in bladder tumor cells may improve BCG treatment. Int $\mathrm{J}$ Mol Med. 2005;16(4):565-71. PMID: 16142388.

15. Cho KH, Hyun JH, Chang YS, Na YG, Shin JH, Song KH. Expression of nitric oxide synthase and aquaporin-3 in cyclophosphamide treated rat bladder. Int Neurourol J.14(3):149-56. doi: 10.5213/inj.2010.14.3.149. PMID: 21179332; PMCID: PMC2998401.

16. Salim EI, Morimura K, Menesi A, El-Lity M, Fukushima S, Wanibuchi H. Elevated oxidative stress and DNA damage and repair levels in urinary bladder carcinomas associated with schistosomiasis. International journal of cancer. 2008;123(3):601-8. doi: 10.1002/ijc.23547. PMID: 18478569. 
Молчанов Р.М., Шпонька І.С. Імуногістохімічному оцінка рака сечового міхура на тлі хронічного запалення.

Реферат. Мета дослідження - встановлення наявності зв'язку експресії маркерів CD95, p53, Ki-67, Bcl-2, BAX, Е-кадгерінов, $\beta$-Катенін, ЦОГ-2, eNOS i iNOS з наявністю супутнього запального процесу у хворих на рак сечового міхура. Виконано імуногістохімічне дослідження експресії зазначених маркерів в біоптатах, отриманих у 44 хворих на рак сечового міхура, розділених на 2 групи порівняння відповідно до наявності супутньої інфекції сечових шляхів. Встановлено підвищення експресії ЦОГ-2 і iNOS а також зміни характеру зв'язку експресії маркерів проліферації, апоптозу та клітинної адгезії в групах порівняння, які можуть бути причиною зміни характеру перебігу пухлинного процесу на тлі запалення.

Ключові слова: рак сечового міхура CD95, p53, Ki-67, Bcl-2, BAX, Е-кадгерин, $\beta$-катенин, ЦОГ-2, eNOS, iNOS. 